Article

\title{
Fullerene-to-MWCNT Structural Evolution Synthesized by Arc Discharge Plasma
}

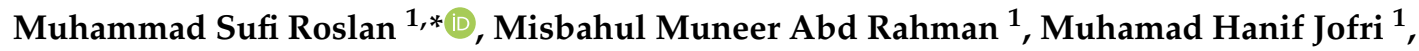 \\ Kashif Tufail Chaudary ${ }^{2}$, Azam Mohamad ${ }^{2}$ and Jalil Ali ${ }^{2}{ }^{\mathbb{D}}$ \\ 1 Center for Diploma Studies (CeDS), Universiti Tun Hussein Onn Malaysia (UTHM), Muar 84600, Malaysia; \\ muneer@uthm.edu.my (M.M.A.R.); mhanif@uthm.edu.my (M.H.J.) \\ 2 Laser Center, Ibnu Sina Institute of Scientific and Industrial Research (ISI-SIR), \\ Universiti Teknologi Malaysia, Johor Bahru 81310, Malaysia; kashif@utm.my (K.T.C.); \\ azammohamad88@gmail.com (A.M.); jalilali@utm.my (J.A.) \\ * Correspondence: sufi@uthm.edu.my
}

Received: 7 September 2018; Accepted: 16 October 2018; Published: 25 October 2018

\begin{abstract}
The growth of multi-walled carbon nanotubes (MWCNTs) has been extensively studied using electron microscopy. The ex situ structural behavior was examined to investigate the growth of the MWCNTs under different environments and pressures using electron microscopy. The arc discharge plasma technique was applied to synthesize the MWCNTs by evaporating carbon through the arc plasma between two cylindrical graphite rods, with a background pressure of $10^{-2}$ to $10^{2}$ mbar, inside a vacuum chamber under different ambient environments. The results showed that long MWCNT structures were successfully grown. We suggest that the mechanism involves: (i) fullerene formation; (ii) the elongation of fullerenes; and (iii) the growth of MWCNTs. Agglomeration with other structures then forms MWCNT bundles. We note that the pressure and environment in the vacuum chamber can affect the structure of the MWCNTs.
\end{abstract}

Keywords: carbon nanotube; nanostructured; arc discharge; electron microscopy

\section{Introduction}

Carbon nanomaterials will have numerous applications in future technologies due to their extraordinary electrical, thermal, and mechanical properties, which make carbon nanomaterials one of the most commonly studied materials. Carbon nanotubes mostly grow at high temperatures of up to $2000{ }^{\circ} \mathrm{C}$. The routes of carbon nanotube formation could be initiated pyrolytically in the gas phase or catalytically, with the catalyst supporting growth. The pyrolytic route involves the bottom-up organic approach, using, for example, benzene [1], coal, [2] and vapor-grown carbon fibers [3] to grow MWCNT structures. The catalyst-assisted growth of MWCNTs is used to essentially control the height and diameter of the carbon nanotube. Arc discharge plasma was the first method to synthesis the carbon nanotube [4]. This method applies an electrical breakdown between two graphite electrodes inside a vacuum chamber that is normally filled with hydrocarbon or inert gases. Arc discharge plasma is one of the most effective techniques for growing carbon nanotubes and other materials, including graphene [5,6], as it provides a fast process with a large-scale production of MWCNTs [7]. Using the arc discharge plasma method to grow MWCNTs can possibly be done in both ways, either using a catalytic approach [8], by inserting a catalyst (usually metal) into a hollow anode, or using non-catalytic [9] approaches. It is important to understand the growth mechanism of carbon nanotubes and their structural behavior in order to exploit the full potential of MWCNTs based on the electron microscopy technique, because the large clusters evolve from the building block of the small cluster. 


\section{Formation of Long MWCNT Structures}

The growth of MWCNTs using the arc discharge plasma method is strongly dependent on the ambient environment, as the residual gas significantly contributes to the kinetics of carbon ions. This phenomenon occurs once a plasma reaction has been sustained and the collision between ions is greatly influenced by the background environment. The background pressure of the plasma is also persistently responsible for cooling down the carbon ion that is massively ejected from the plasma to form the nanostructure. By referring to the micrograph images captured for the MWCNT samples that were obtained from different environments, we could identify the growth behavior of the MWCNT structures along with the other carbon nanostructures that were formed during the synthesis process.

The growth behavior of MWCNTs in the air environment, examined under transmission electron microscope (TEM), is shown in Figure 1. During the arc discharge process carried under the air environment, clear MWCNTs were preferentially obtained. For the discharge process carried out at a preferentially low-pressure environment of $10^{-2}$ mbar, long and straight MWCNT structures of up to few $\mu \mathrm{m}$ in length had grown. The TEM image depicted in Figure 1 shows a long carbon nanotube structure grown by encapsulating a small carbon nanotube.

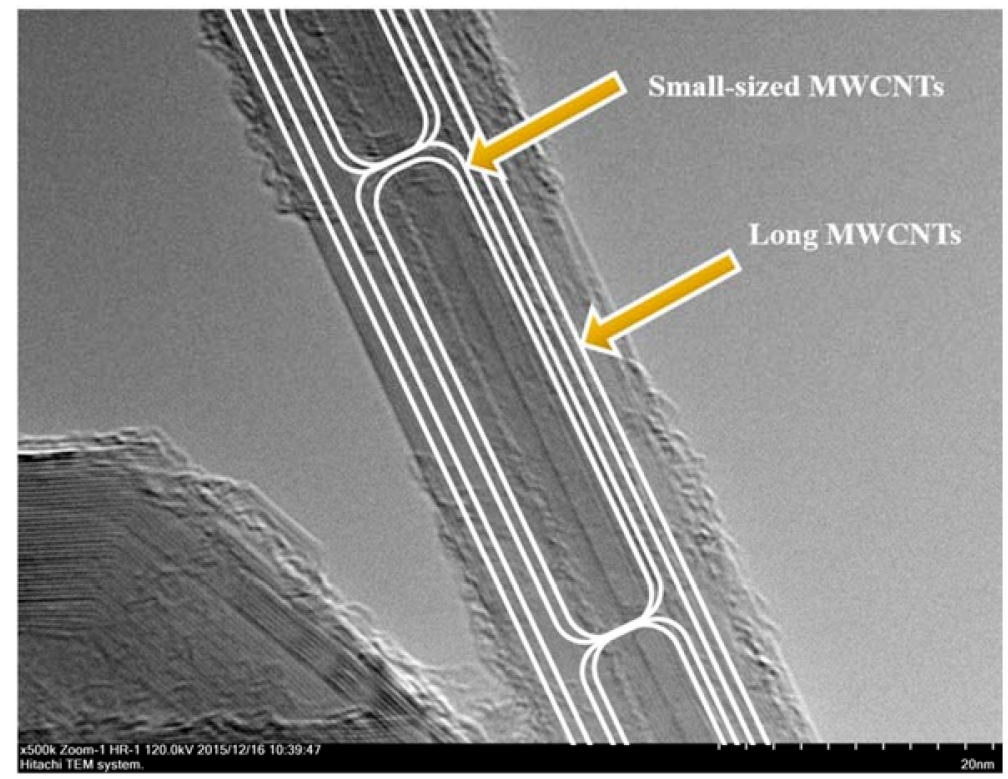

Figure 1. Long multi-walled carbon nanotube (MWCNT) that is formed by encapsulating smaller carbon nanotubes (CNTs).

In order to understand the structural formation, we have to understand the formation of the smallest carbon cluster, before getting to the biggest one. It begins with the recombination of carbon atoms bound in the form of closed, three-dimensional cages, known as fullerene, or also sometimes called "buckyball", in the plasma periphery, which is the cold region where the charged particle is recombined and neutralized [10]. The grown lightweight fullerene freely floats around the region between the inter-electrodes, far from the arc plasma setup where plasma formation is favored. By the time the fullerene gets close to the MWCNT, the tip of the MWCNT, which is highly positively charged at a high temperature [11], is easily attracted to the fullerene, which is negatively charged [12], thus recombining with the MWCNT body. This phenomenon is captured in Figure 2, which shows the attachment of the fullerene to the tip of the MWCNT. The fullerene then keeps growing, and elongates to form a small-structure MWCNT. As time passes by, the outermost large-structure MWCNTs cover the small-structure MWCNTs with a new layer of carbon, which eventually encapsulates the small-MWCNT structure. 


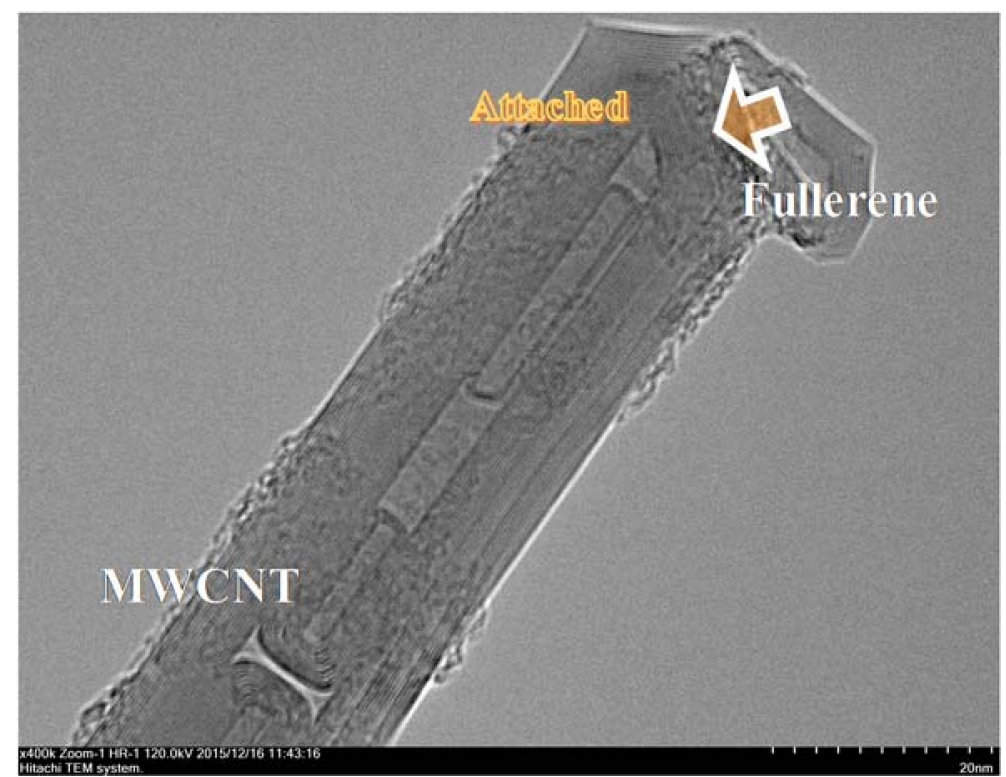

Figure 2. Attachment of the fullerene grown on the MWCNT tip, forming a long MWCNT structure so as to form a long MWCNT chain.

This proves that the long tube structure had evolved, due to the combination of the small tube structures that were ultimately wrapped and formed long tube structures, as depicted in Figures 1 and 2.

\section{Growth Mechanism of MWCNT Structures}

Several mechanisms of MWCNT growth have been proposed, including root-based growth [13,14]; fluidized-state growth, which can be represented by the Arrhenius-type plot [15]; and tip growth [16-18]. In this study, we believe that the MWCNTs grew from the fullerene base structure, based on evidence shown in the microscopic images that we obtained. The study showed that upon reaching the activation energy, the growth rate of the carbon nanotube was conceivably independent of the diameter and chiral angle [19].

The growth of MWCNT potentially starts from the formation of the fullerene itself, as the enormous formation of fullerene structures on the side of MWCNTs. The base (some prefer substrate) plays an important role, as it acts as an anchor for the early stage of growth for the MWCNT [20]. The first possibility is the growth of a few layered MWCNT structures, which potentially start from the base growth method, which uses the tip of the end-cap fullerene as the base. The feeding of the carbon ion emerges from evaporating the arc plasma into the fullerene cap, then evolving, layer by layer, from the outer wall of the MWCNT structure until, at a specific circumference, the growth stops to form a small MWCNT structure. This process is repeated until it forms a chain of small MWCNTs. When the growth of the MWCNT chain is limited, the enriched carbon ion again surrounds it, then wraps around the chain and forms a long MWCNT structure, as shown in Figure 3. The TEM image in Figure 3 shows a view of the intermediate process in the formation of MWCNTs, where the multiple layers of fullerene start to elongate to form a tubular structure. The image clearly shows that the outermost layer of fullerene elongates faster than the innermost layer. This is to ensure that the innermost layer will maintain the tubular structure in order to form the MWCNT. The phenomenon of fullerene elongation is illustrated in Figure 4. 


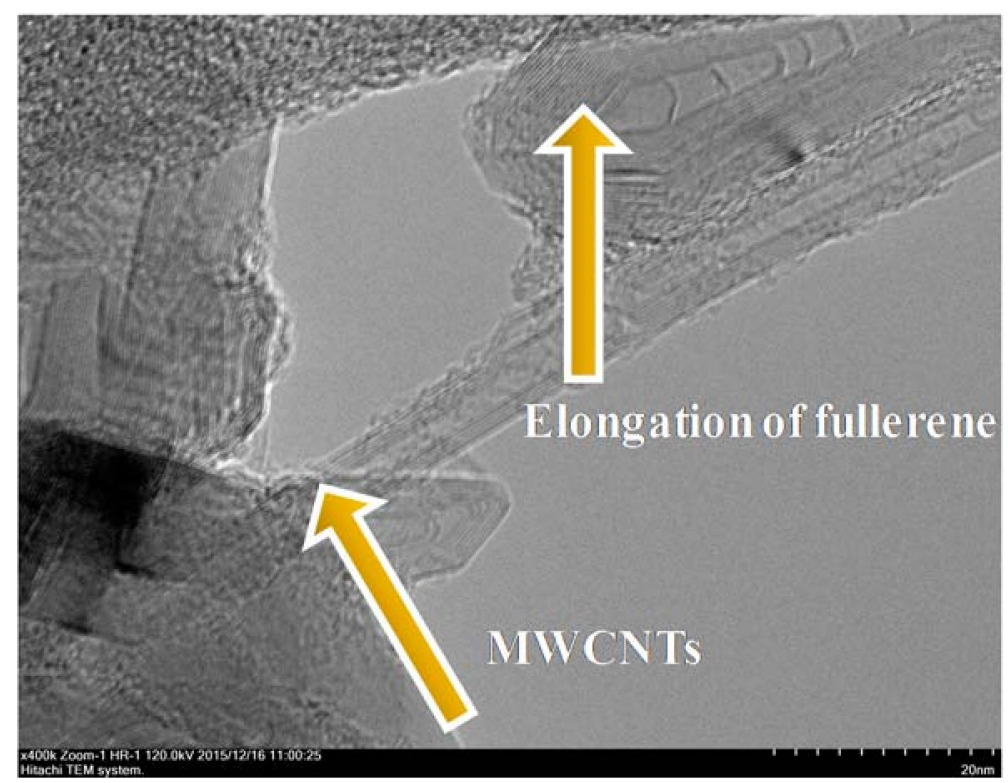

Figure 3. Elongation of the fullerene to form the MWCNT structure.

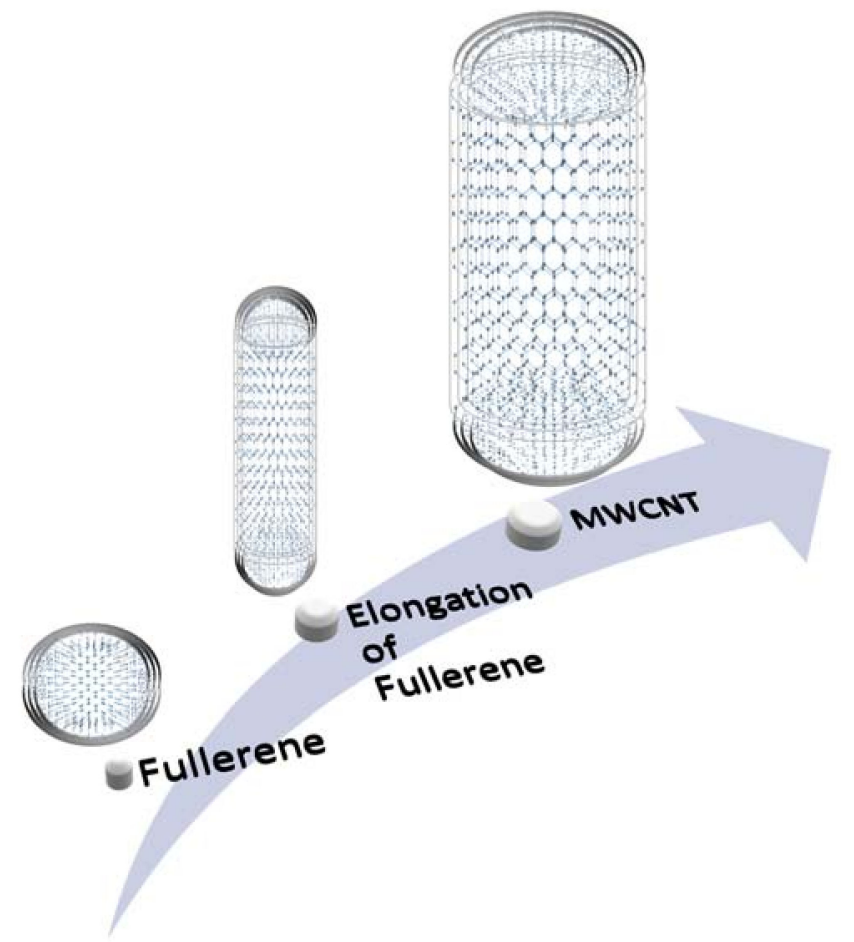

Figure 4. Illustration of fullerene's evolution to form the MWCNT structure.

The second possible explanation of the MWCNT growth structure is that it forms at the base of the graphene layer. Fullerene growing from the plasma falls into the graphene layer. Later, this will become the growth base of the MWCNTs structure as the fullerene continues to increase in length due to the deposition of carbon ions and radicals that emerged from the plasma into the body. This relation can be seen on the TEM image depicted in Figure 5 and illustrated in Figure 6. The growth of MWCNT on graphene was reported in [21], using the chemical vapor deposition (CVD) method, even though it requires a long synthesis period. 


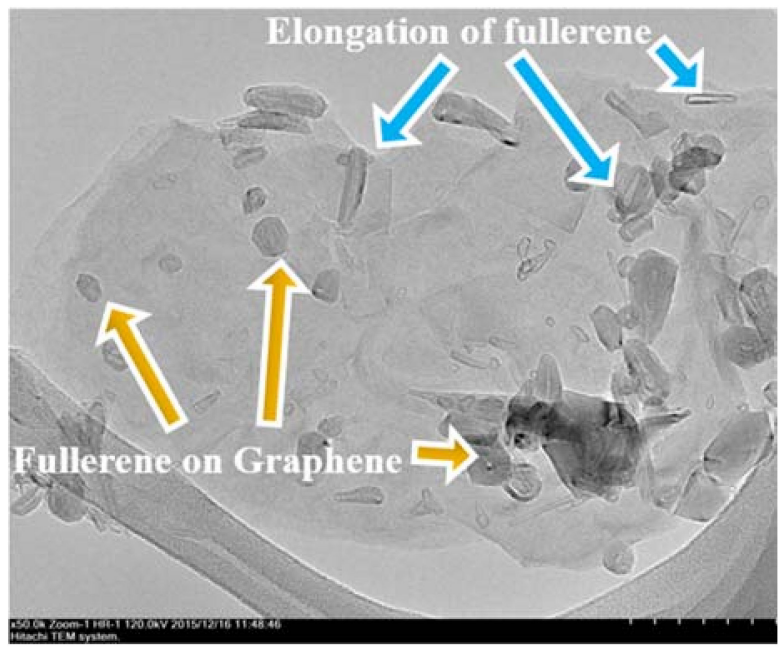

(a)

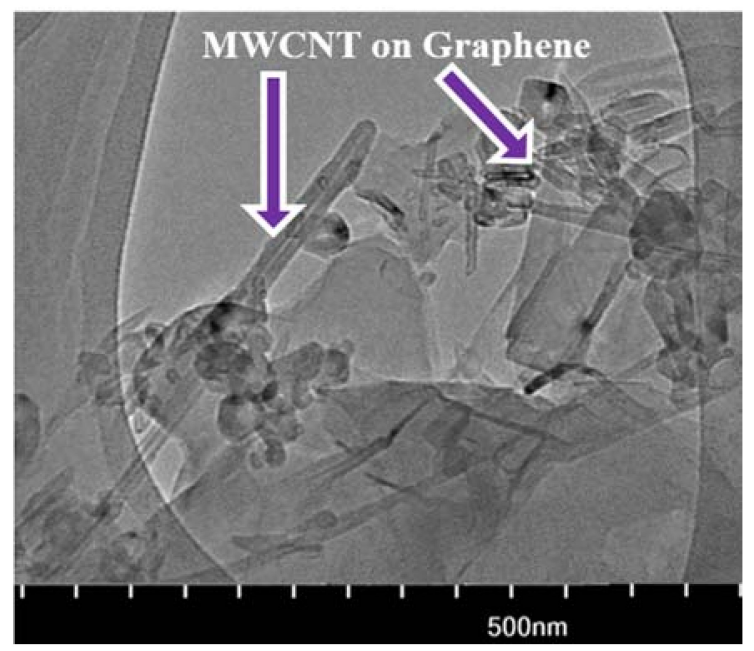

(b)

Figure 5. (a) Attachment of fullerene on graphene and (b) the MWCNT-on-graphene.

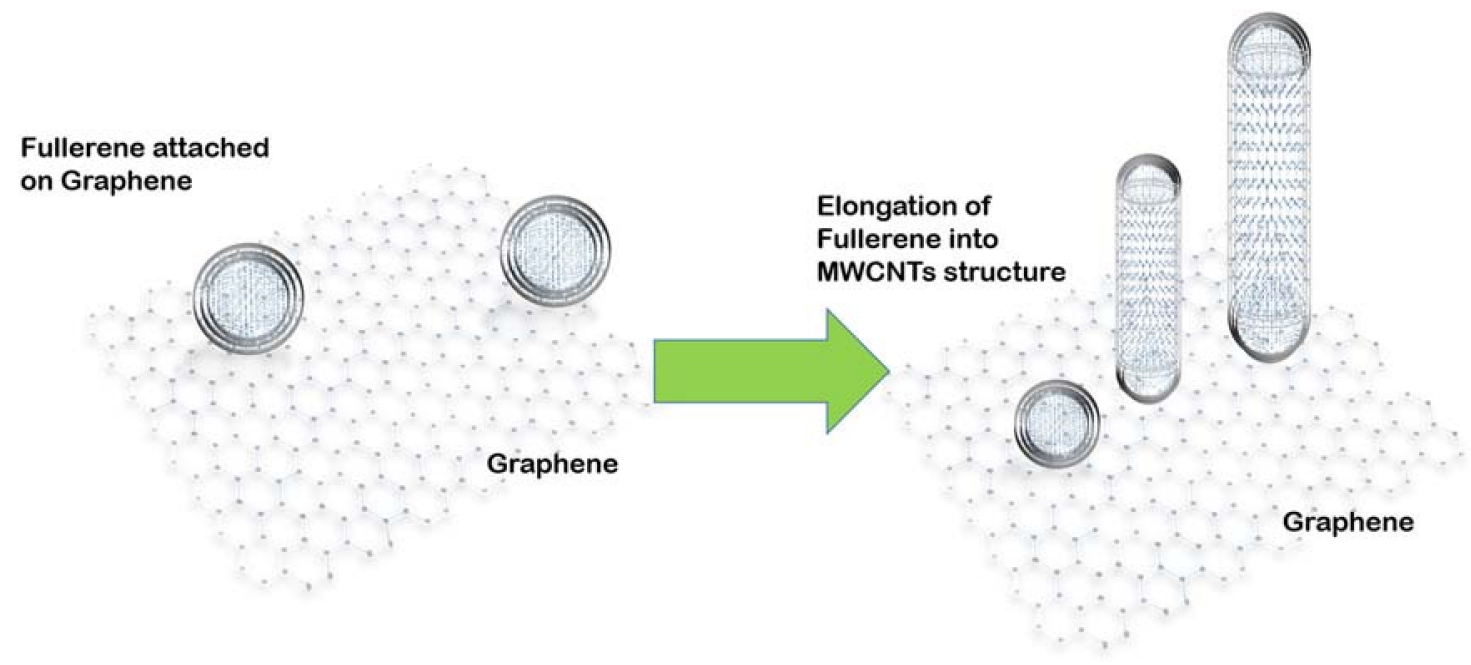

Figure 6. Concept chart of the growth of the MWCNT on graphene.

The third possible route for the growth of MWCNTs is the formation and elongation of fullerene floating in the air. When the carbon ion combined to form the $\mathrm{C}_{60}$ fullerene, the seeding of the carbon ion at the fullerene surface led to the formation of a tubular structure. By interval time, the MWCNT continued to grow in terms of layers and length. The MWCNTs that formed in the floating air as the tube were extremely lightweight and can be driven by the change of pressure in the environment. The tip of the MWCNT cap was highly active as discussed in an earlier section, which can cause bonding with other structures. This can happen when many of the MWCNT structures float and are driven by the hydrodynamic pressure of plasma into certain areas. After this, the MWCNT will bind together and form a bundle of MWCNT. This phenomenon was captured on the TEM and field emission scanning electron microscope (FESEM) images shown in Figure 7 and illustrated by the concept chart in Figure 8. 


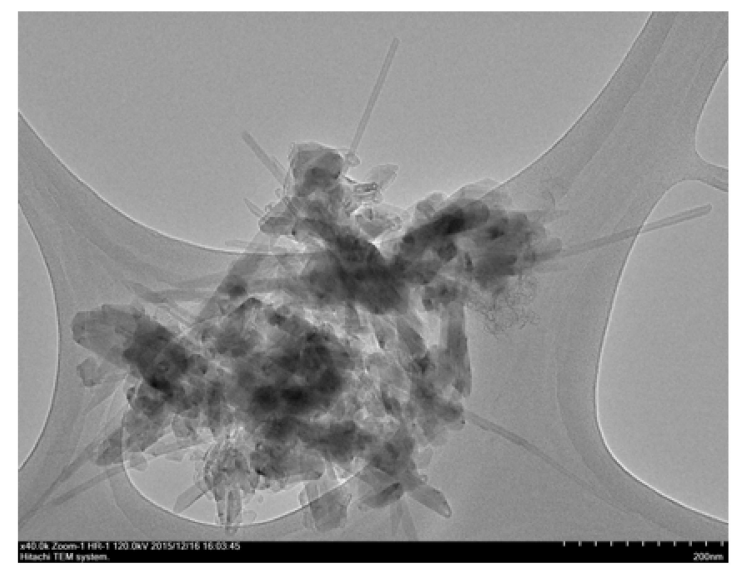

(a)

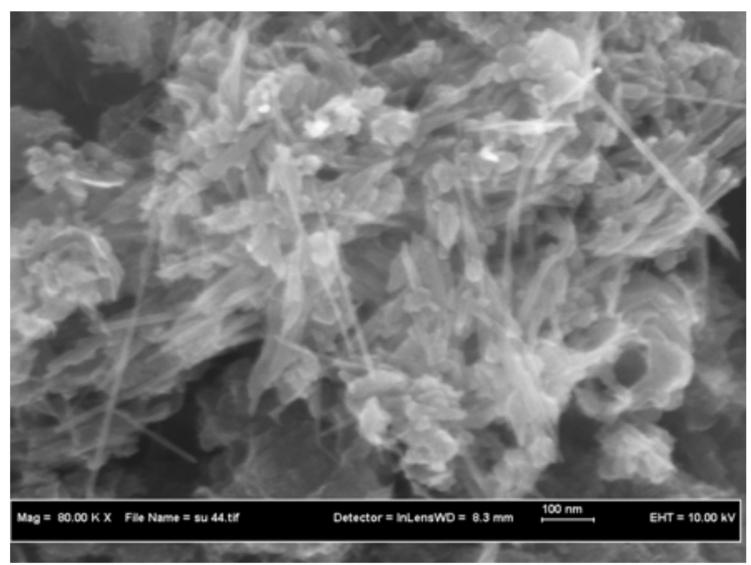

(b)

Figure 7. Formation of the MWCNT bundle as monitored in (a) transmission electron microscope (TEM) and (b) field emission scanning electron microscope (FESEM) images.

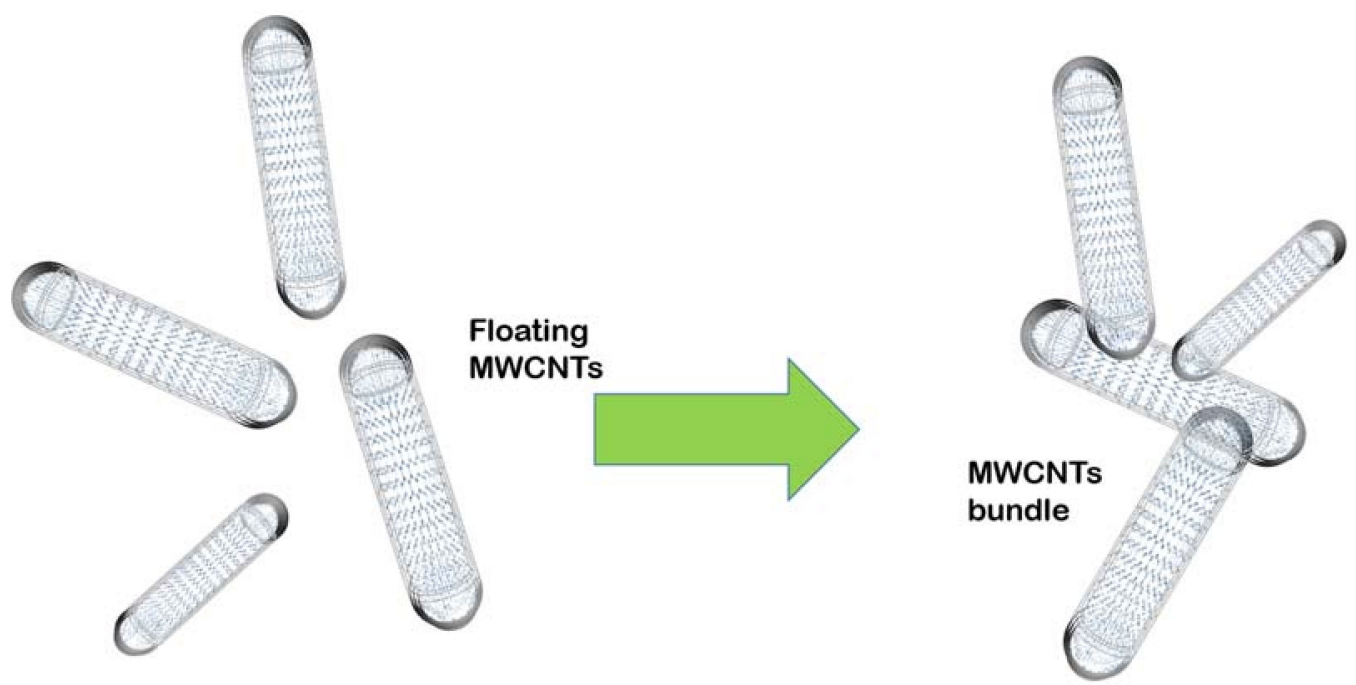

Figure 8. Concept chart of the formation of the MWCNT bundle.

\section{Pressure- and Environment-Dependence of the Growth of the MWCNT Long Structure}

Structural Changes with Different Background Pressures

Figure 9 shows the MWCNT structure synthesized by the arc discharge plasma technique with different background pressures. The growth phenomenon of the MWCNT change according to the environment is simplified in the chart presented in Figure 10. 


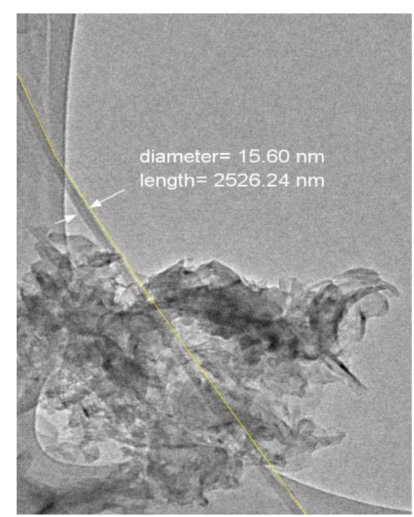

(a)

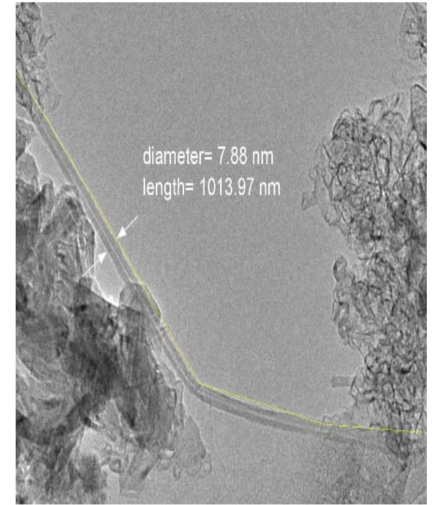

(d)

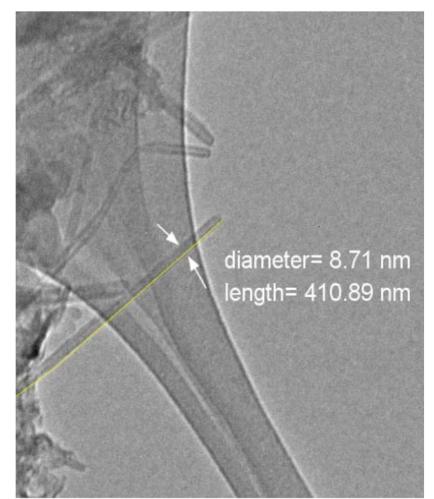

(g)

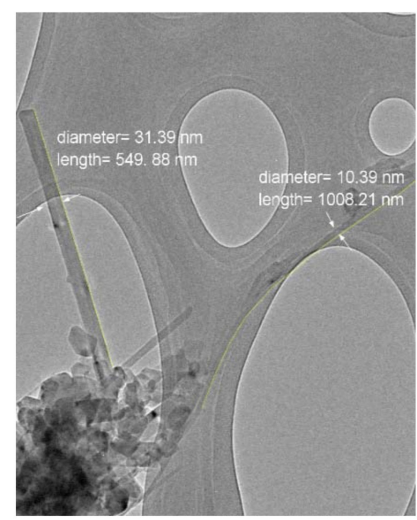

(b)

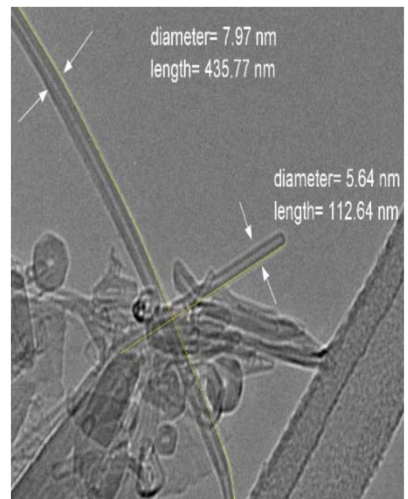

(e)

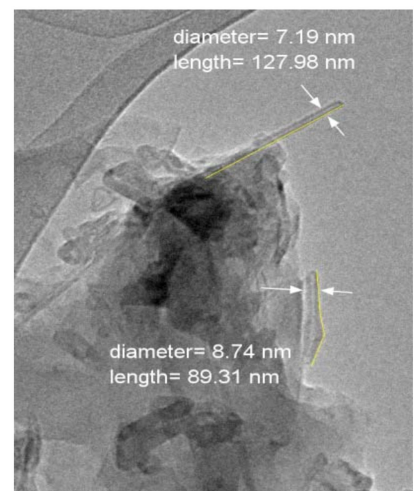

(h)

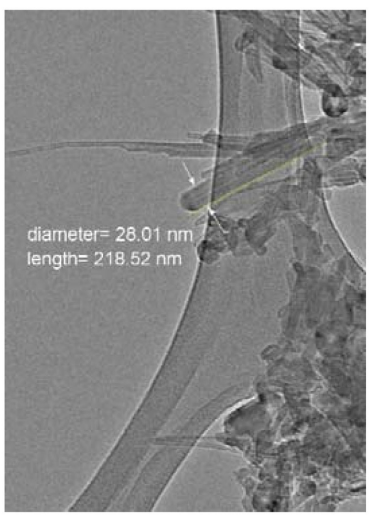

(c)

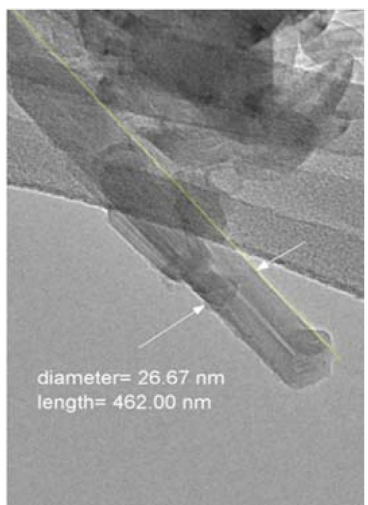

(f)

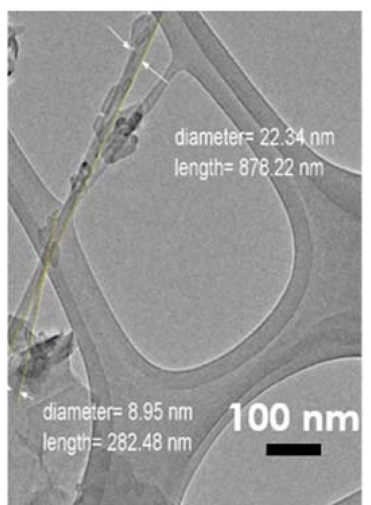

(i)

Figure 9. TEM images of the MWCNT growth by the arc discharge plasma with different environments and background pressures: at $10^{-2}, 1$, and $10^{2} \operatorname{mbar}(\mathbf{a}-\mathbf{c})$ air; $(\mathbf{d}-\mathbf{f}) \mathrm{Ar}$; and $(\mathbf{g}-\mathbf{i}) \mathrm{H}_{2}$ (all images are in same scale bar). 


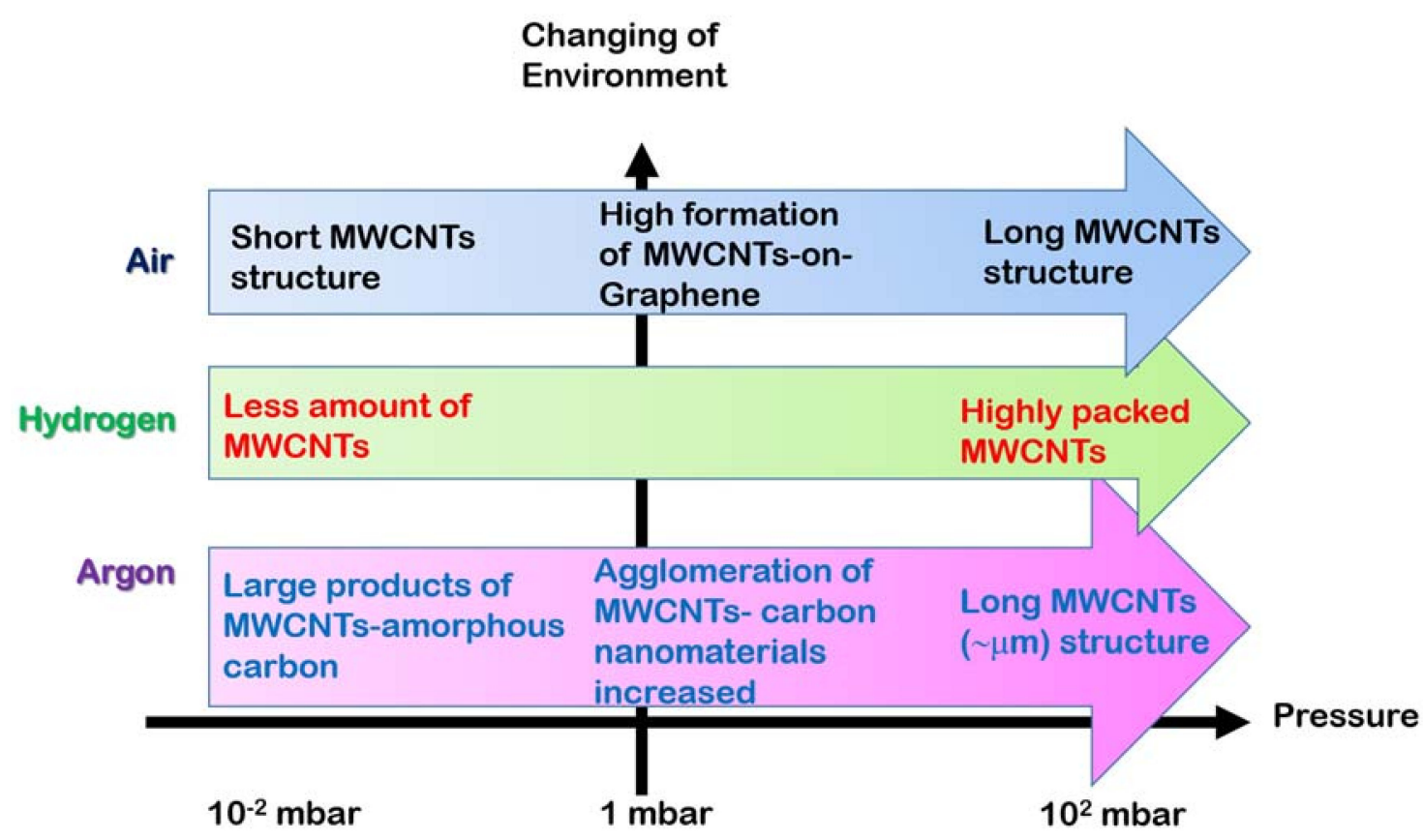

Figure 10. Growth phenomenon of the MWCNT in different environments and at different pressures.

In the air environment with no other gases introduced into the chamber, the trend was clear and the carbon nanotube length was limited under low background pressure $\left(10^{-2} \mathrm{mbar}\right)$. However, as the ambient pressure increased, the formation of the MWCNTs-on-graphene was more favorable. When the background pressure rose to $10^{2} \mathrm{mbar}$, the formation of the long carbon nanotube structure progressed closer to $600 \mathrm{~nm}$.

Based on the TEM analysis, it was found that the inner walls tended to build up greater in the hydrogen environment, compared to the other environments. The inner and outer diameters of the carbon nanotubes played a crucial role in the growth of the MWCNT structure when the inner tube maintained the structure of the MWCNT. Meanwhile, the outer layer took precedence over the inner layer and formed a multi-layer structure according to the density function theory (DFT), as calculated in [22]. It was observed that a lesser amount of MWCNT formed under a low background pressure $\left(10^{-2}\right.$ mbar) of hydrogen compared with the high background pressure of $10^{2}$ mbar.

Inert gases are mostly used as a buffer gas in MWCNT formation [8,23], as it is favorable to sustaining the ignition of the arc plasma and avoiding the reaction during the formation of the carbon nanocluster. In this study, according to the TEM image captured, the formation of the MWCNT tended to increase in diameter (as well as in the number of walls formed) within an increment of background Ar with pressure from $10^{-2}$ to $10^{2}$ mbar, as shown in Figure 8d-f. Under low background pressure $\left(10^{-2}\right.$ mbar) most of the carbon structures formed were amorphous (non-ordered), while at $1 \mathrm{mbar}$ pressure, MWCNTs formed and agglomerated with other carbon nanomaterials, including graphene and fullerene, as depicted in Figure 11. 


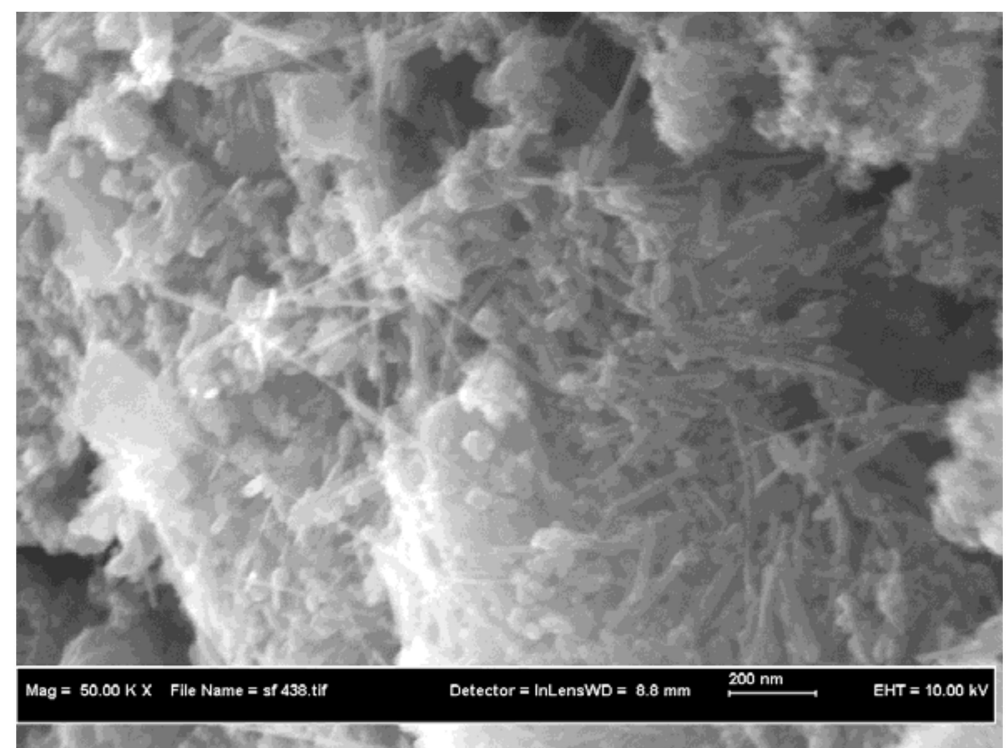

Figure 11. Agglomeration of the MWCNTs with other carbon nanomaterials synthesized in Ar ambient at 1 mbar pressure.

\section{Materials and Methods}

The carbon nanomaterial sample was grown by establishing the arc plasma between two graphite rods inside a vacuum chamber. The pressure inside the chamber was reduced to the base pressure of $10^{-5}$ mbar before introducing $\mathrm{Ar}$ and $\mathrm{H}_{2}$ gas. An air environment enriched with $70 \%$ of $\mathrm{N}_{2}$ gas also was applied for comparison.

The discharge process initiated by the contacting anode and cathode terminal of the graphite rod is shown in Figure 12. The arc discharge was carried out with a voltage $12 \mathrm{~V}$ and a current of $90 \mathrm{~A}$. An external magnetic field with a field strength of $30 \mathrm{mT}$ was applied to sustain the arc discharge process by the magnetic confinement phenomenon. The carbon nanomaterial was collected from the cathode and the chamber. The collected carbon nanomaterial samples were analyzed using transmission electron microscopy and field emission scanning electron microscopy.

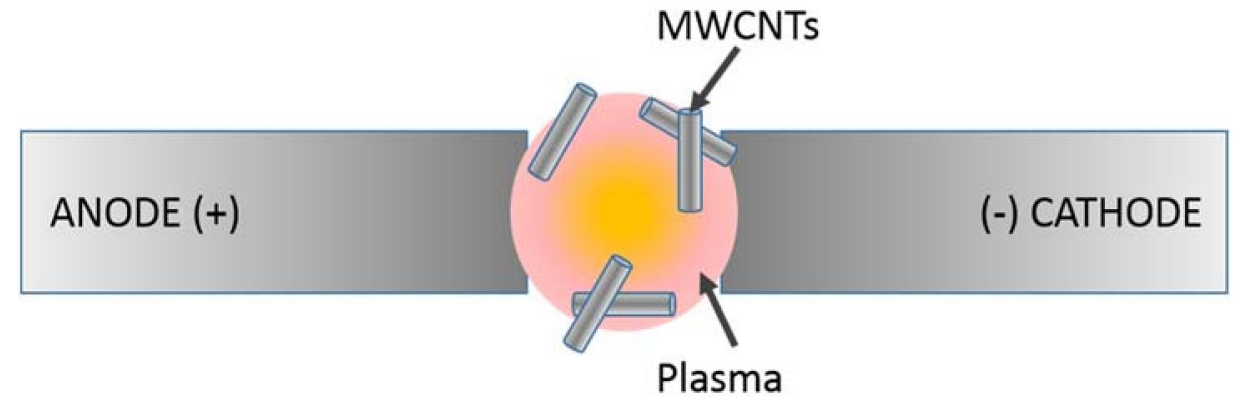

Figure 12. The MWCNT synthesized by the arc discharge plasma.

\section{Conclusions}

The study of the MWCNT growth using the arc discharge plasma method used the TEM technique reveal that the formation of the MWCNT could occur in several way: (i) formation of long MWCNT structures by encapsulating the small structure of the MWCNT chains; (ii) fullerene lies on the graphene layer and becomes a substrate for growing the MWCNTs; and (iii) formation of the MWCNT in the cold plasma region, with the MWCNT stacking together to form MWCNT bundles. This study showed that the anchoring and elongation of fullerene in certain areas acts as a seed to form the tubular tube structures known as MWCNTs. The background environment and pressure play a crucial role in forming the carbon nanoclusters, especially the carbon nanotubes, and the background environment 
and the pressure should be at a certain level, especially at high pressure $\left(10^{2} \mathrm{mbar}\right)$ in $\mathrm{H}_{2}, \mathrm{Ar}$, and air. The formation of the MWCNTs was not favorable at a low $\mathrm{H}_{2}$ pressure $\left(10^{-2} \mathrm{mbar}\right)$ and Ar pressure ( $1 \mathrm{mbar}$ ), as it contained a lot of nanoclusters and disrupt the lengthening of the tube. Therefore, it is important to develop an understanding of the formation of small carbon clusters that steer into the formation of the superior structure of the carbon nanotubes.

Author Contributions: K.T.C. and M.S.R. conceived and designed the experiments; A.M. contributed to analyze the data; M.M.A.R. and M.H.J assisted in visualization, M.S.R and J.A. wrote and reviewed the paper.

Funding: This research was funded by Research Management Center (RMC) Universiti Tun Hussein Onn Malaysia under grant Tier-1 vot U929.

Acknowledgments: Special thanks to S.K. Mariam for proofreading the article.

Conflicts of Interest: The authors declare no conflict of interest.

\section{References}

1. Benito, A.M.; Maniette, Y.; Muñoz, E.; Martínez, M.T. Carbon nanotubes production by catalytic pyrolysis of benzene. Carbon 1998, 36, 681-683. [CrossRef]

2. Moothi, K.; Simate, G.S.; Falcon, R.; Iyuke, S.E.; Meyyappan, M. Carbon nanotube synthesis using coal pyrolysis. Langmuir 2015, 31, 9464-9472. [CrossRef] [PubMed]

3. Endo, M.; Takeuchi, K.; Kobori, K.; Takahashi, K.; Kroto, H.W.; Sarkar, A. Pyrolytic carbon nanotubes from vapor-grown carbon fibers. Carbon 1995, 33, 873-881. [CrossRef]

4. Iijima, S. Helical microtubules of graphitic carbon. Nature 1991, 354, 56-58. [CrossRef]

5. Roslan, M.S.; Chaudary, K.T.; Haider, Z.; Zin, A.F.M.; Ali, J. Effect of magnetic field on carbon nanotubes and graphene structure synthesized at low pressure via arc discharge process. AIP Conf. Proc. 2017, 1284, 030025.

6. Volotskova, O.; Levchenko, I.; Shashurin, A.; Raitses, Y.; Ostrikov, K.; Keidar, M. Single-step synthesis and magnetic separation of graphene and carbon nanotubes in arc discharge plasmas. Nanoscale 2010, 2, 2281-2285. [CrossRef] [PubMed]

7. Levchenko, I.; Volotskova, O.; Shashurin, A.; Raitses, Y.; Ostrikov, K.; Keidar, M. The large-scale production of graphene flakes using magnetically-enhanced arc discharge between carbon electrodes. Carbon 2010, 48, 4570-4574. [CrossRef]

8. Keidar, M.; Levchenko, I.; Arbel, T.; Alexander, M.; Waas, A.M.; Ostrikov, K. Increasing the length of single-wall carbon nanotubes in a magnetically enhanced arc discharge. Appl. Phys. Lett. 2008, 92, 043129. [CrossRef]

9. Roslan, M.S.; Chaudhary, K.T;; Doylend, N.; Agam, A.; Kamarulzaman, R.; Haider, Z;; Mazalan, E.; Ali, J. Growth of wall-controlled MWCNTs by magnetic field assisted arc discharge plasma. J. Saudi Chem. Soc. 2018. [CrossRef]

10. Keidar, M.; Shashurin, A.; Volotskova, O.; Raitses, Y.; Beilis, I.I. Mechanism of carbon nanostructure synthesis in arc plasma. Phys. Plasmas 2010, 17, 57101. [CrossRef]

11. An, Z.; Toda, M.; Ono, T. Comparative investigation into surface charged multi-walled carbon nanotubes reinforced $\mathrm{Cu}$ nanocomposites for interconnect applications. Compos. Part B Eng. 2016, 95, 137-143. [CrossRef]

12. Hampe, O.; Neumaier, M.; Blom, M.N.; Kappes, M.M. On the generation and stability of isolated doubly negatively charged fullerenes. Chem. Phys. Lett. 2002, 354, 303-309. [CrossRef]

13. Hsu, C.M.; Lin, C.H.; Lai, H.J.; Kuo, C.T. Root growth of multi-wall carbon nanotubes by MPCVD1. Thin Solid Films 2005, 471, 140-144. [CrossRef]

14. Shokry, S.A.; El Morsi, A.K.; Sabaa, M.S.; Mohamed, R.R.; El Sorogy, H.E. Study of the productivity of MWCNT over $\mathrm{Fe}$ and $\mathrm{Fe}-\mathrm{Co}$ catalysts supported on $\mathrm{SiO}_{2}, \mathrm{Al}_{2} \mathrm{O}_{3}$ and MgO. Egypt. J. Pet. 2014, 23, 183-189. [CrossRef]

15. Kumar, M.; Ando, Y. Controlling the diameter distribution of carbon nanotubes grown from camphor on a zeolite support. Carbon 2005, 43, 533-540. [CrossRef]

16. He, M.; Yang, T.; Shang, D.; Xin, B.; Chernov, A.I.; Obraztsova, E.D.; Sainio, J.; Wei, N.; Cui, H.; Jiang, H.; et al. High temperature growth of single-walled carbon nanotubes with a narrow chirality distribution by tip-growth mode. Chem. Eng. J. 2018, 341, 344-350. [CrossRef] 
17. Bistamam, M.S.A.; Azam, M.A. Tip-growth of aligned carbon nanotubes on cobalt catalyst supported by alumina using alcohol catalytic chemical vapor deposition. Res. Phys. 2014, 4, 105-106. [CrossRef]

18. Saeidi, M. Effect of interaction between AC electric field and phonon oscillation of metal cluster on tip-growth of carbon nanotube. Phys. E Low Dimens. Syst. Nanostruct. 2015, 70, 225-230. [CrossRef]

19. Kharlamova, M.V.; Kramberger, C.; Sato, Y.; Saito, T.; Suenaga, K.; Pichler, T.; Shiozawa, H. Chiral vector and metal catalyst-dependent growth kinetics of single-wall carbon nanotubes. Carbon 2018, 133, $283-292$. [CrossRef]

20. Kunadian, I.; Andrews, R.; Qian, D.; Mengüç, M.P. Growth kinetics of MWCNTs synthesized by a continuous-feed CVD method. Carbon 2009, 47, 384-395. [CrossRef]

21. Zhao, J.; Xing, B.; Yang, H.; Pan, Q.; Li, Z.; Liu, Z. Growth of carbon nanotubes on graphene by chemical vapor deposition. New Carbon Mater. 2016, 31, 31-36. [CrossRef]

22. Liu, J.; Liu, L.; Lu, J.; Zhu, H. The formation mechanism of chiral carbon nanotubes. Phys. B Condens. Matter 2018, 530, 277-282. [CrossRef]

23. Su, Y.; Zhang, Y.; Wei, H.; Yang, Z.; Kong, E.S.-W.; Zhang, Y. Diameter-control of single-walled carbon nanotubes produced by magnetic field-assisted arc discharge. Carbon 2012, 50, 2556-2562. [CrossRef]

(C) 2018 by the authors. Licensee MDPI, Basel, Switzerland. This article is an open access article distributed under the terms and conditions of the Creative Commons Attribution (CC BY) license (http:/ / creativecommons.org/licenses/by/4.0/). 